\title{
A Comparative study of Agomelatine and Ramelteon for Attenuation of Haemodynamic response to Laryngoscopy and Endotracheal Intubation
}

\author{
Pradeep Hosagoudar ${ }^{1}$, Arunashree $\mathrm{S}^{2}$, M. Venkateswara Pradeep ${ }^{3}$ \\ ${ }^{1}$ Professor, Department of Anaesthesiology, East Point College of Medical Sciences and Research, Bangalore, ${ }^{2}$ Senior Resident, Department of \\ Anaesthesiology, Karwar Institute of Medical Sciences, Karwar, Karnataka. ${ }^{3}$ Senior Resident, Department of Anaesthesiology, P.E.S. Institute of Medical \\ Sciences and Research, Kuppam, Andhra Pradesh.
}

\section{Abstract}

Background: Pressor response to laryngoscopy and endotracheal intubation is a well recognised clinical entity, and many medications have been used for its attenuation. Agomelatine and Ramelteon are analogues of Melatonin which have been recently used for preoperative anxiolysis and sedation with less known effects on pressor response. Subjects and Methods: 60 ASA-I patients scheduled for elective surgeries under general anaesthesia were randomly allocated into 2 equal groups. Group-A (Tab.agomelatine $10 \mathrm{mg}$ ) and Group-R (Tab.ramelteon $8 \mathrm{mg}$ ) were administered per oral 1 hour prior to induction of anaesthesia. Heart rate and blood pressure were assessed preoperatively and at $0,1,3,5,10,15$ minutes. Results: Reduction heart rate and blood pressure were noted when compared to baseline in both the groups $(\mathrm{p}<0.05)$. However there was no statistical difference between the two groups at various intervals of time and were comparable ( $>0.05$ ). Conclusion: Oral agomelatine and ramelteon when administered 1 hour prior to induction of anaesthesia, resulted in comparable reduction of heart rate and blood pressure response to laryngoscopy and endotracheal intubation.

Keywords: laryngoscopy, endotracheal intubation, agomelatine, ramelteon.

Corresponding Author: Dr. Arunashree S, Senior Resident, Department of Anaesthesiology, Karwar Institute of Medical Sciences, Karwar, Karnataka.

Received: May 2019

Accepted: May 2019

\section{Introduction}

Laryngoscopy and endotracheal intubation are considered potent noxious stimuli which provoke haemodynamic responses leading to a marked increase in heart rate and blood pressure. ${ }^{[1]}$ This would be of little significance in healthy individual but are detrimental in individuals who have limited myocardial reserve due to coronary artery disease, cardiac dysrhythmias, congestive heart failure, hypertension, cardiomyopathy and geriatric age group. ${ }^{[2]}$

During intubation of trachea, the laryngeal and tracheal sensory receptors are stimulated which result in the release of endogenous catecholamines resulting in tachycardia and hypertension, ${ }^{[3]}$ as a response of sympathetic stimulation. Hence, it is important to take measures to attenuate these pressor responses.

Since the invention of laryngoscopy and endotracheal intubation, various drug regimens and techniques have been used to attenuate stress responses. Some of such agents being opioids (fentanyl, alfentanil), calcium channel blockers(verapamil, diltiazem), sympatholytics (clonidine, dexmedetomidine and methyldopa), beta blockers(esmolol, propranolol), benzodiazepines(midazolam, alprazolam) and peripheral vasodilators(sodium nitroprusside, nitroglycerine). ${ }^{[4]}$ However, each medication has its own limitation e.g. respiratory depression, hypotension, tachycardia, bradycardia, rebound hypertension or allergic reactions. Hence, there has always been a need for a better agent.

Melatonin ( $\mathrm{N}$-acetyl-5-methoxy tryptamine), is a naturally occurring neurohormone secreted by pineal gland in humans from the amino acid tryptophan. ${ }^{[5-7]}$ It has a wide range of safety margin. It has been used at a dose of $0.4 \mathrm{mg} / \mathrm{kg}$ in children safely.

Several studies reported that melatonin has analgesic potential, thus improves the quality of recovery.8 Considering these facts, the present study was planned to assess the effects of melatonin analogues Agomelatine and Ramelteon premedication on haemodynamic response for laryngoscopy and endotracheal intubation.

\section{Aims and Objectives of the Study}

To compare the effect of preoperative oral Agomelatine and Ramelteon on haemodynamic response to laryngoscopy and endotracheal intubation.

\section{Subjects and Methods}


0

After receiving the institutional ethical committee approval and satisfying all the inclusion criteria, a prospective randomized control study was conducted on sixty ASA class I patients of either gender, between the age of 18 to 60 years, who were scheduled for elective surgery under general anaesthesia at P.E.S. Institute of Medical sciences and Research between the year 2016 to 2018. Written and informed consent were obtained from the patients and were allocated into two equal groups: Agomelatine group(A) and the Ramelteon group $(\mathrm{R})$, of thirty patients each.

Keeping the power of study at $80 \%$ and alpha-error (confidence intervals) at $95 \%$, the minimal sample size in each group was 20 . However we included 30 patients in each group to make up for possible drop outs and better validation of results.

Patients of ASA-I, aged between18-60, weighing between 40 $-70 \mathrm{kgs}$ and giving valid written and informed consent were included in the study. Patient refusal, age more than 60 years or less than 18years, ASA-II and above, pregnant or lactating women, sinus Bradycardia/Heart Block/Conduction defects, Ischemic Heart Diseases(IHD)/Rheumatic Heart Disease, Renal Diseases with impaired renal parameters, COPD and Bronchial Asthma or any Respiratory diseases, patients with hepatic diseases, known Allergy to Agomelatine or Ramelteon or Melatonin, patients with Head injury or Psychiatric illness or preoperative haemodynamic instability.

Preanaesthetic assessment was done one day prior to the surgery. A detailed history of present and past medical illness and systemic examination were done. They were advised Nil per oral for 8 hours for solids/juice/milk and 3 hours for water. Patients were randomly assigned to 2 groups $\mathrm{A}$ and $\mathrm{R}$ based on a computer generated random numbers. After recording baseline vitals and re-evaluation, patients in Group-A received Tab.agomelatine $10 \mathrm{mg}$ orally, whereas those in Group- $\mathrm{R}$ group received Tab.ramelteon $8 \mathrm{mg}$. The patients and Anaesthesiologist recording the observations were blinded to the drug administered. The study medication was taken with sips of water by the patient, 60 minutes before induction time, by a Resident who was not involved in study. An Anaesthesiologist blinded to the randomization sequence and premedication monitored the heart rate, blood pressure before shifting to OT and after laryngoscopy at 0,1 , $3,5,7,10,15$ minutes.

Intraoperative monitoring included ECG, SpO2, NIBP and Capnography. Following 5 minutes of preoxygenation, Inj.Fentanyl $2 \mathrm{mcg} / \mathrm{kg}$ was administered intravenously. Induction of anaesthesia was done Inj.Propofol $2 \mathrm{mg} / \mathrm{kg}$ over 15 seconds into a rapidly flowing IV infusion until the loss of response to verbal commands and loss of eyelash reflex, and Inj. Vecuronium $0.1 \mathrm{mg} / \mathrm{kg}$ i.v. to facilitate laryngoscopy and intubation. Intraoperative maintenance of anaesthesia was with Nitrous oxide in Oxygen (60:40) with titrated dose of Isoflurane. At the end of surgery the patients were reversed with Inj.neostigmine and Inj.glycopyrrolate and extubated after confirming, complete reversal of neuromuscular blockade and meeting criteria for extubation.

Heart Rate and NIBP were recorded before pre-medication, and following laryngoscopy at $0,1,3,5,7,10,15$ minutes. Occurrence of side effects like headache, nausea, enuresis, depression and dizziness were noted if any.

\section{Statistical analysis}

Data was expressed as mean \pm standard deviation (SD) or absolute values. Qualitative data were compared with the Chi square test and fisher's exact test. Quantitative variables were compared with the student ' $t$ ' test. Statistical software: The Statistical software namely SAS 9.2, SPSS 15.0, Stata 10.1, MedCalc 9.0.1,Systat 12.0 and $\mathrm{R}$ environment ver.2.11.1 were used for the analysis of the data and Microsoft word and Excel were used to generate graphs, tables etc. The level of statistical significance was set at $\mathrm{p}<0.05$.

\section{Results}

60 patients undergoing different elective surgical procedure under General Anaesthesia were divided randomly into 2 groups with 30 patients in each group as mentioned in methods. Patients were comparable with respect to age, gender, weight among the two groups.

Table 1: Demographic \& other basic data of the patients
\begin{tabular}{|l|l|l|l|}
\hline $\begin{array}{l}\text { Patient } \\
\text { characteristics }\end{array}$ & $\begin{array}{l}\text { Agomelatine } \\
\text { group }\end{array}$ & $\begin{array}{l}\text { Ramelteon } \\
\text { group }\end{array}$ & 'p' value \\
\hline Number of patients & 30 & 30 & \\
\hline $\begin{array}{l}\text { Age(yrs) (Mean } \\
\pm \text { SD) }\end{array}$ & $37.26 \pm 9.74$ & $36.63 \pm 9.4$ & 0.827 \\
\hline Sex(M:F) & $15: 15$ & $20: 10$ & 1.367 \\
\hline Weight & $55.9 \pm 8.31$ & $55.7 \pm 8.03$ & 0.744 \\
\hline ASA grade I & 30 & 30 & \\
\hline
\end{tabular}

Table 2: Comparison of heart rate (bpm) between the groups.
\begin{tabular}{|l|l|l|l|}
\hline $\begin{array}{l}\text { Heart rate } \\
\text { (bpm) }\end{array}$ & $\begin{array}{l}\text { Agomelatine } \\
\text { group }\end{array}$ & $\begin{array}{l}\text { Ramelteon } \\
\text { group }\end{array}$ & 'p' value \\
\hline $\begin{array}{l}\text { Day before } \\
\text { surgery }\end{array}$ & $81.5 \pm 5.817$ & $80.06 \pm 5.57$ & 0.970 \\
\hline $\begin{array}{l}\text { On day of } \\
\text { surgery }\end{array}$ & $84.66 \pm 6.26$ & $84.73 \pm 6.26$ & 0.04 \\
\hline 0 min & $83.86 \pm 5.894$ & $83.46 \pm 5.50$ & 0.27 \\
\hline 1 min & $83.33 \pm 5.54$ & $82.86 \pm 5.72$ & 0.32 \\
\hline $3 \mathrm{~min}$ & $80.06 \pm 5.37$ & $81.06 \pm 5.37$ & 0.003 \\
\hline $5 \mathrm{~min}$ & $78.733 \pm 4.74$ & $78.73 \pm 5.64$ & 0.02 \\
\hline $7 \mathrm{~min}$ & $77.2 \pm 5.65$ & $76.2 \pm 4.25$ & 0.04 \\
\hline $10 \mathrm{~min}$ & $75.26 \pm 4.96$ & $75.0 \pm 4.71$ & 0.21 \\
\hline $15 \mathrm{~min}$ & $73.0 \pm 5.058$ & $71.33 \pm 3.87$ & 1.41 \\
\hline
\end{tabular}

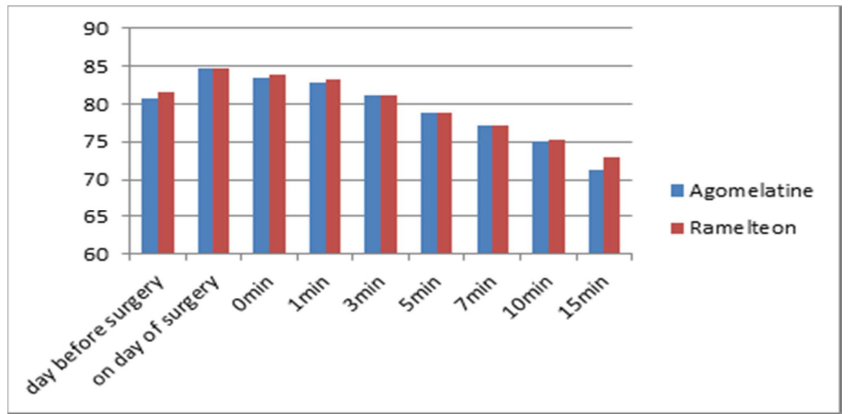

Figure 1: Comparison of HR (bpm) between the groups.

The mean baseline heart rates were not comparable between the groups. A decrease in heart rate from baseline in Agomelatine group and Ramelteon group was noted after premedication. Both groups showed a decrease in heart rate at $0,1,3,5,10,15$ minutes which were statistically insignificant. Both the groups showed decrease in heart rate 
0

after premedication.

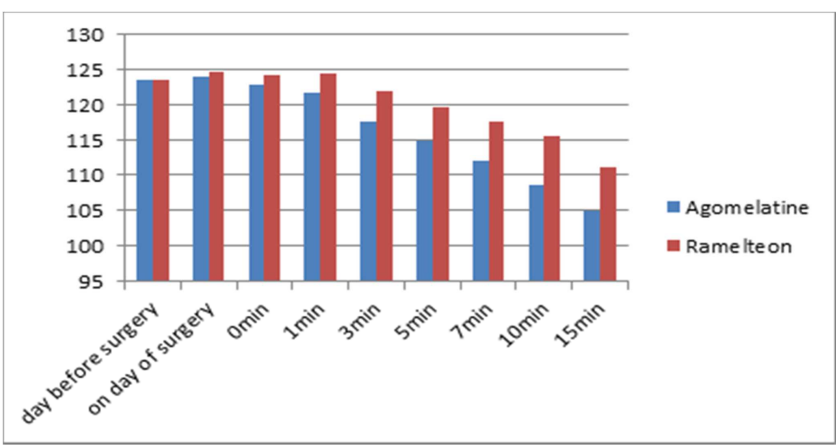

Figure 2: Comparison of SBP $(\mathrm{mm} \mathrm{Hg})$ between the groups.

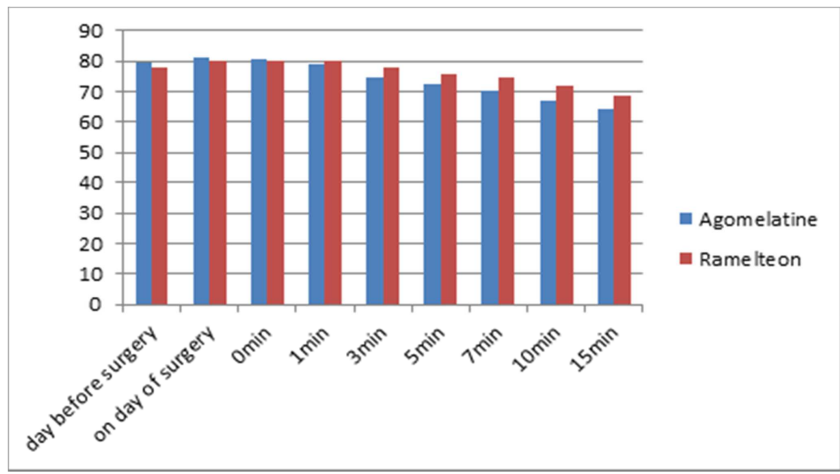

Figure 3: Comparison of DBP (mm Hg) in between the groups.

The mean baseline Diastolic blood pressure(DBP) at $0,1,3,5,7,10$ and 15 minutes decreased in both the groups, but the difference was statistically insignificant.

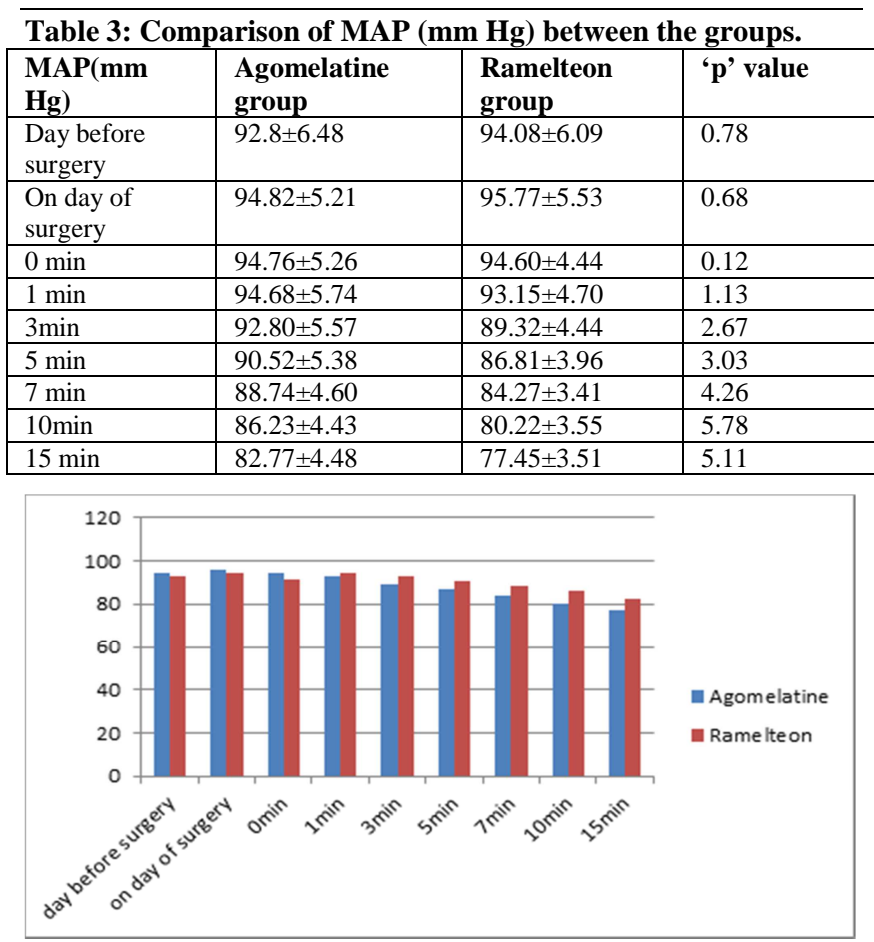

Figure 4: Comparison of MAP(mm Hg) between the groups.

Compared to baseline, a drop in Mean Arterial blood pressure at $0,1,3,5,7,10,15$ minutes was noted in both the groups but the difference was statistically insignificant.

\section{Discussion}

Physiological roles of melatonin include sleep induction and maintenance, ${ }^{[10]}$ analgesic effects, ${ }^{[11-13]}$ anti-inflammatory and immunological effects and anti-oxidative effect. ${ }^{[13-16]}$ Melatonin has a mild hypotensive effect and the mechanism of action on the circulation is complex and unclear. Melatonin may bind to specific melatonin receptors in the blood vessels, interfering with the vascular response to catecholamines. ${ }^{[17]}$ Melatonin has a hypnotic and sedative effect when administered orally. ${ }^{[9]}$ This may be due to its circadian rhythm regulation effect. Perioperatively, melatonin has potential uses like decreasing the blood pressure, neuro-protective role and to improve surgical outcomes. ${ }^{[17]}$

A study was done comparing the role of oral melatonin in doses of $6 \mathrm{mg}$ and $9 \mathrm{mg}$, in attenuating pressor response to laryngoscopy and intubation, when administered 1 hour prior to surgery. A reduction of blood pressure with regard to systolic, diastolic and mean blood pressure; and perfusion index in both melatonin groups as compared to the placebo group (Mohammad et al) were noted.

Two melatonin agonists namely ramelteon and agomelatine have been approved by the FDA for long-term use for the treatment of insomnia. ${ }^{[18,19]}$ The advantage of melatonin analogues is their good safety profile because of specificity for two principal melatonin receptors: MT1 and MT2. ${ }^{[18]}$

Agomelatine is a synthetic naphthalene analogue of melatonin with a longer half-life (mean terminal half-life of 140 minutes) and affinity for these receptors than melatonin91. Agomelatine is well absorbed $(\geq 80 \%)$ after oral administration. The peak plasma concentration is reached within 1 to 2 hours. Volume of distribution is about 35 liters and plasma protein binding is $95 \%$. Agomelatine is rapidly metabolised via hepatic enzymes CYP1A2, CYP2C9 and CYP2C19 to its major inactive metabolites, hydroxylated and demethylated agomelatine and eliminated in urine. ${ }^{[20]}$

Ramelteon has high selectivity and affinity for melatonin MT1 and MT2 receptors undergoes rapid, ${ }^{[21,22]}$ high first-pass metabolism, and exhibits linear pharmacokinetics. Ramelteon is absorbed rapidly, peak concentrations occurring at approximately 0.75 hour (range $0.5-1.5$ hours) after oral administration. Although, the total absorption of ramelteon is at least $84 \%$, the absolute oral bioavailability is only $1.8 \%$ due to extensive first-pass metabolism. ${ }^{[22]}$ Its protein binding is approximately $82 \%$, independent of concentration, has a volume of distribution of $73.6 \mathrm{~L}$. It is metabolised by CYP1A2, CYP2C and CYP3A4 isozymes. Hence the purpose of this study was to examine the effectiveness of oral melatonin analogues Agomelatine and Ramelteon to assess haemodynamic response for laryngoscopy and intubation in ASA-I adult patients, undergoing elective surgeries under general anaesthesia.

The peak effect of Agomelatine and Ramelteon ranges from 60- 150 minutes, hence we chose to give the drug, 60 minutes before induction. ${ }^{[2]}$ There was no significant difference between the groups in view of their age, sex and weight characteristics. In fact, increases in heart rate and blood pressure are among the signs used to detect inadequate depth of anaesthesia by anaesthesiologists. Therefore, the difference in heart rate and blood pressure at the different 
0

time intervals of the study compared to the baseline value would be an indication of a subject's level of anxiety, with higher levels being related to higher degrees of anxiety.

The mean basal heart rate on day before surgery were comparable between the two group $(\mathrm{p}=0.97)$. Inter group comparison shows statistically significant $(p<0.001)$ difference in the heart rate measured at on day of surgery $1,3,5,7$ minute intervals. Heart rate was statistically insignificant on day before surgery $0,1,10,15$ minutes as $\mathrm{p}$ value is $>0.05$.

[Table 2 and 3] shows the comparison of systolic blood pressure (SBP), diastolic blood pressure (DBP) and mean arterial blood pressure (MAP) between the two groups respectively. The mean systolic blood pressure, diastolic blood pressure and the mean arterial pressure were not comparable between the two groups on the day before surgery, before premedication and at 0 1,3,5,7,10, $15 \mathrm{~min}$ after premedication ( $\mathrm{p}>0.5)$.

There was statistically insignificant difference $(\mathrm{P}>0.05)$ in SBP. DBP and MAP at on day before surgery, on day of surgery $0,1,3,5,7,10,15$ minutes after medication. Both the groups $\mathrm{A}$ and $\mathrm{R}$ showing decrease in SBP, DBP, MAP gradually from 0 to 15 minutes but not significant as comparing each other.

In Agomelatine group, the decrease in blood pressures from base line was seen at 15 min and the maximum decrease was at 60 minute. The change may be due to the anxiolytic and sedative effect of Agomelatine. These changes at different interval after premedication correlates well with the decrease in anxiety scores and increase in sedation scores after premedication.

In Ramelteon group, the decrease in blood pressures from base line was seen at 15 min and the maximum decrease was at 60 minute. The change may be due to the anxiolytic and sedative effect of Ramelteon. These changes at different interval after premedication correlates well with the decrease in anxiety scores and increase in sedation scores after premedication. However in both the groups show decrease in blood pressure and attenuate the intubation response. There were no adverse effects seen with the dosage of $0.2 \mathrm{mg} / \mathrm{kg}$ used during the study period.

\section{Conclusion}

Oral Agomelatine and Ramelteon administered orally, 60 minutes before induction of anaesthesia, has impact on heart rate and blood pressure. Both the drugs display, comparable attenuation of heart rate and blood pressure changes to laryngoscopy and endotracheal intubation response.

\section{References}

1. Henderson J. Airway management in the adult. In: Miller RD, editor.
Miller's Anaesthesia. 7th ed. Philadelphia: Churchill Livingstone; 2010. p. 1573610 .

2. Gill NP, Wright B, Reilly CS. Relationship between hypoxaemic and cardiac ischaemic events in the perioperative period. $\mathrm{Br} \mathrm{J}$ Anaesth 1992;68:471 3 .

3. Brian JP, Norton ML. Principles of airway management. In: Healy TE, Knight PR, editors. Wylie and Churchill Davidson's. 7th ed. London: Arnold Press; 2003. p. 443.

4. Ugur B, Ogurlu M, Gezer E, Nuri Aydin O, Gürsoy F. Effects of esmolol, lidocaine and fentanyl on haemodynamic responses to endotracheal intubation: A comparative study. Clin Drug Investig 2007;27:269 77.

5. Cathi E Dennecry \& Candy Tsouroubnis :Dietary Supplements \& Herbal Medication In: Bertram G Katzung, Susan B. Masters, Anthony J Trevor editors. Basic and Clinical Pharmacology 12th edition, Mc Graw Hill 2012, P1125-113

6. Melatonin Monograph: Ahern Med Rev 200510 (4):326-36

7. Paul F. White, Matthew R. Eng.Ambulatory- (Outpatient) AnesthesiaIn:Ronald D. Miller, Lars I, Eriksson, Lee A. Fleisher, Jeanine P, Wiener-Kronis, William LYoung, editors. Miller's Anesthesia 7thedition.USA: Natasha Andjelkovic; 2010, p2419-2459

8. Zeev N, Kain et al: Pre-operative melatonin and its effects on induction and emergence in children undergoing anaesthesia and surgery. Anaesthesiology 2009; 111:44-9.

9. Naguib M. Gottumukkala V, Goldstein PA. Melatonin and Anesthesia: a clinical perspective. Journal of Pineal Research 2007; 42: 12-21.

10. Dennely CE, Sourouivs CT. Dietary supplements and herbal medications. In: BetramG Katzung, Susan B Masters, Antony J Trevor, Editors. Basic and Clinical Pharmacology, 11th ed. Newyork: The McGraw Hill Companies; 2009.p1123-4

11. Wilhelmsen M, Amirian I, Reiter RJ, Rosenberg J, Gogenur I. Analgesic effects of melatonin: a review of current evidence from experimental and clinical studies. J Pineal Res 2011:51:270-277

12. Dai X, Cui SG, L1 SR, Chen Q, Wang R. Melatonin attenuates the development of antinociceptive tolerance to delta but not to mu-opioid receptor agonist in mice. Behav Brain Res 2007;182:21-27

13. Si. Ll SR, Wang R, Dai X, Chen Q. Melatonin enhances antinociceptive effects of delta, but not mu-opioid agonist in mice. Brain Res 2005; 1043:132-138.

14. Reiter RJ, Garcia JJ, Pie J. Oxidative toxicity in models of neurodegeneration: responses to melatonin. Restorative Neurology and Neuroscience 1998; 12(2-3):135 142.

15. Reiter RJ. Tan DX, Fuentes-Broto L. Melatonin: a multitasking molecule. Progress in Brain Research 2010; 181:127-151.

16. Benitez- King G, Tunez I, Bellon A, Ortiz GG, Anton- Tay F. Melatonin prevents cytoskeletal alteration and oxidative stress induced by okadaic acid in NIE-115 cells. Experimental Neurology 2003; 182(1):151-159.

17. Gitto E, Romeo C. Reiter RJ, Impellizzeri P, Pesce S, Basile M, et al.Melatoninreduces oxidative stress in surgical neonates. Journal of Paediatric surgery 2004; 39(2):184-189.

18. Arendt J, RajaratnamShantha MW. Melatonin and its agonists: An update. The British Journal of Psychiatry 2008; 193:267-269.

19. Cardinali DP, Srinivasan V, Brzezinski A, Brown GM. Melatonin and its analogs in insomnia and depression. J Pineal Res 2011; 52(4):365-75.

20. Buoli M., Mauri M.C., Altamura A.C. Pharmacokinetic evaluation of agomelatine for the treatment of generalised anxiety disorder. Expert Opin.Drug Metab.Toxicol.2014;10:885-892.

21. Greenblatt DJ, Harmatz JS, Karim A. Age and gender effects on the pharmacokinetics and pharmacodynamics of ramelteon, a hypnotic agent acting via melatonin receptors MT1 and MT2. J ClinPharmacol. 2007;47:485-496.

22. Kato K, Hirai K, Nishiyama K, et al. Neurochemical properties of ramelteon (TAK-375), a selective MT1/MT2 receptor agonist. Neuropharmacology. 2005;48(2):301-310.

Copyright: (c) the author(s), publisher. Academia Anesthesiologica International is an Official Publication of "Society for Health Care \& Research Development". It is an open-access article distributed under the terms of the Creative Commons Attribution Non-Commercial License, which permits unrestricted non-commercial use, distribution, and reproduction in any medium, provided the original work is properly cited.

How to cite this article: Hosagoudar P, Arunashree S, Pradeep MV. A Comparative study of Agomelatine and Ramelteon for Attenuation of Haemodynamic response to Laryngoscopy and Endotracheal Intubation. Acad. Anesthesiol. Int. 2019;4(2):4-7.

DOI: dx.doi.org/10.21276/aan.2019.4.2.2

Source of Support: Nil, Conflict of Interest: None declared. 